\title{
Overview of seismic monitoring and assessment of seismic hazard based on a decade of seismic events
}

\author{
Praveena Das Jennifer, VR Balasubramaniam and \\ K Goverdhan \\ National Institute of Rock Mechanics \\ Bengaluru, India \\ pravi.jenniferdas@gmail.com
}

\author{
GP Ganapathy \\ Vellore Institute of Technology University \\ Vellore, India
}

\begin{abstract}
During mining activity, the natural equilibrium of the rock mass gets altered resulting in increase in stress causing sudden, violent failure of rock mass. The stress increases with increase in the depth of mining. The dynamic stress changes caused due to release of strain energy from within the rock mass in the form of seismic signals are termed as seismic events. The occurrence of seismic events has been a regular phenomenon in and around the abandoned mines of Kolar Gold Fields causing damage to the surface structures and inducing apprehension about the safety and stability of mining areas. Among the abandoned mines, one of them had reached mining depth as deep as $3200 \mathrm{~m}$. In this sensitive mining area, there has been occurrence of many seismic events that were monitored by a dedicated seismic monitoring system from time to time. The monitoring system was used to determine the location of seismic events and used as an indicator of precaution from future events. In the background of this monitoring history, an attempt has been made here to assess the overall scenario of seismic hazard due to the seismic events observed over one decade. This study focuses on assessing the current probable seismic hazard for the abandoned mining region by using the estimated source parameters such as source radius, seismic magnitude obtained from the data of strong motion accelerometer supported by data from existing broad band seismometer.
\end{abstract}

Keywords—seismic events, seismic hazard, source radius, seismic magnitude

\section{INTRODUCTION}

The mines of Kolar Gold Fields (KGF) was one of the major source of gold production in India. Gold mining was started in 1880 and as the mines got deeper the energy equilibrium in the rocks changed leading to build up of stress culminating in violent rockbursts. In this area, occurrence of seismic events due to sudden collapse of the underground workings has been a usual phenomenon ever since the beginning of mining operations. The probability of occurrence of seismic events tends to increase as depth of the mine increases. This led to initiation of a series of scientific studies resulting in establishment of seismic monitoring system at KGF mines area. To understand the phenomenon and cause of various seismic events taking place, considerable research has been carried out at KGF employing monitoring system and techniques [1]. Seismic investigation since 1978 and microseismic investigations since 1983 were carried out respectively to monitor occurrence of seismic events and to assess the stability of mine workings. The seismic event monitoring system started since 1979. Years rolled by and as the mining activities were on the waning side and the old mines existed abandoned for a long time. However, the release of stress accumulated in the rocks due to gradual failure of supports, presence of water in the mines [2] and lack adequate mine reclamation measures continued to be factor for cause of regular seismic events witnessed in the area.

Geographically, the mining area is located in Kolar district of Karnataka state, India. Kolar Gold Field is situated at $12^{0} 57^{\prime}$ lattitude North and $78^{\circ} 16^{\prime}$ longitude East lying at $100 \mathrm{~km}$ east of Bangalore in South India having an altitude of $900 \mathrm{~m}$ above mean sea level.

Geologically, Kolar mining region lies in the Kolar Schist Belt of Dharwar Craton of southern peninsular India. The Kolar Schist belt is $80 \mathrm{~km}$ long in the north-south direction and about $4 \mathrm{~km}$ wide in the east-west direction. Located on the Kolar schist belt along a strike length of $8 \mathrm{~km}$ are three mines: the Nundydroog Mine, Champion Reef Mine and Mysore Mine. The three major fault systems identified in this mining region are, the prominent Mysore North Fault (MNF), striking NW-SE right through the centre of the region and the other two identified faults are minor faults running sub parallel to MNF, Tennant Fault and Gifford Fault [2, 3]. Fig 1.shows geology of Kolar Gold Fields

Occurrence of mine induced seismic events have been quite challenging to the mining community as the events endanger lives and loss to property[4]. The attempt to assess seismic hazard integrates the effects of all the seismic events occurring at different locations of mining area during the specified period of mining and post mining, with their associated uncertainties taken into account. Seismic events in mining regions are results of sudden fracturing of rock, redistribution of stress during mining activity, the method of mining adopted, the presence of geological planes of weakness over a period becoming points of slippage, other causes like presence of faults, dykes, or joints.

This paper gives an overview of various instrumentations deployed in the investigation and the techniques adopted for monitoring the seismic events and prediction efforts. Based on the recorded data and the derived parameters an over the 
last decade an attempt has been made here to assess the hazard due to the events.

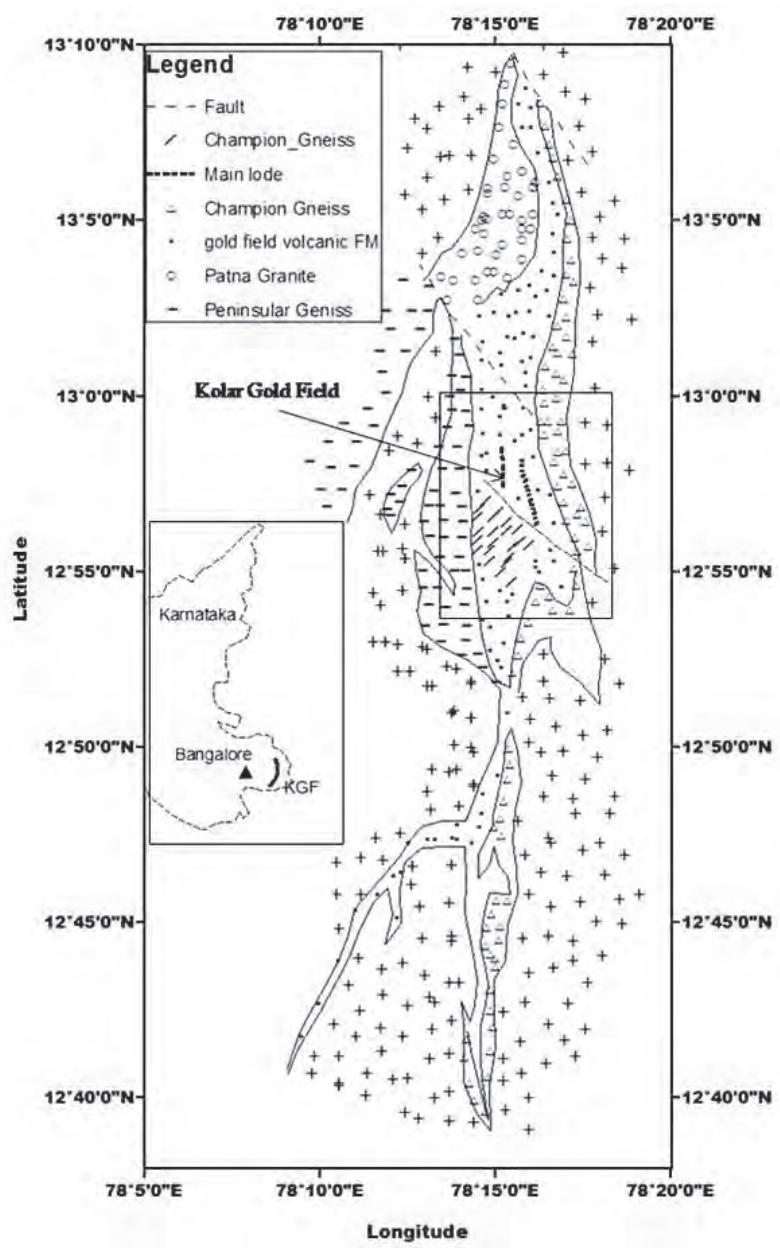

Fig 1.Map showing geology of Kolar Gold Fields [2]

\section{BRIEF OVERVIEW OF PAST SEISMIC MONITORING SYSTEMS}

Monitoring of seismic activity is very important in assessing the stability of underground excavations. The seismic events occurring in the underground mining regions of Kolar Gold Fields had been constantly monitored using seismic monitoring system since 1979. Initially the monitoring systems were used to locate the foci of the seismic events and to obtain timely warning of any impending seismic event. A review on the various types of Seismic Monitoring Systems periodically used in Kolar Gold .Fields, will help in better understanding of the monitoring systems used, the method employed for recording of seismic events, the output source parameters and the method used for assessing the probable seismic hazard for the mining region of KGF.

\section{Seismic Monitoring during 1978 to 1990}

A regional multi-channel seismic network was established in 1978, consisting of 14 Geophones - 7 surface and 7 underground covering the mining area. The network system was put in continuous operation for round the clock monitoring of seismic events in the mining area stretching about $8 \mathrm{~km} \mathrm{N-S}$ and $3 \mathrm{~km}$ wide.

The signals picked up by the sensors were directly transmitted through 4 - core cable using a carrier frequency of 540 hertz, and recorded on a 24 channel analogue magnetic tape recorder as shown in Fig 2. The underground network consist of high frequency geophones accelerometers and the micro-seismic signals picked up by the sensors are telemetered through a 4-core cable and fed to a microprocessor through an interface unit located in the surface laboratory[5].

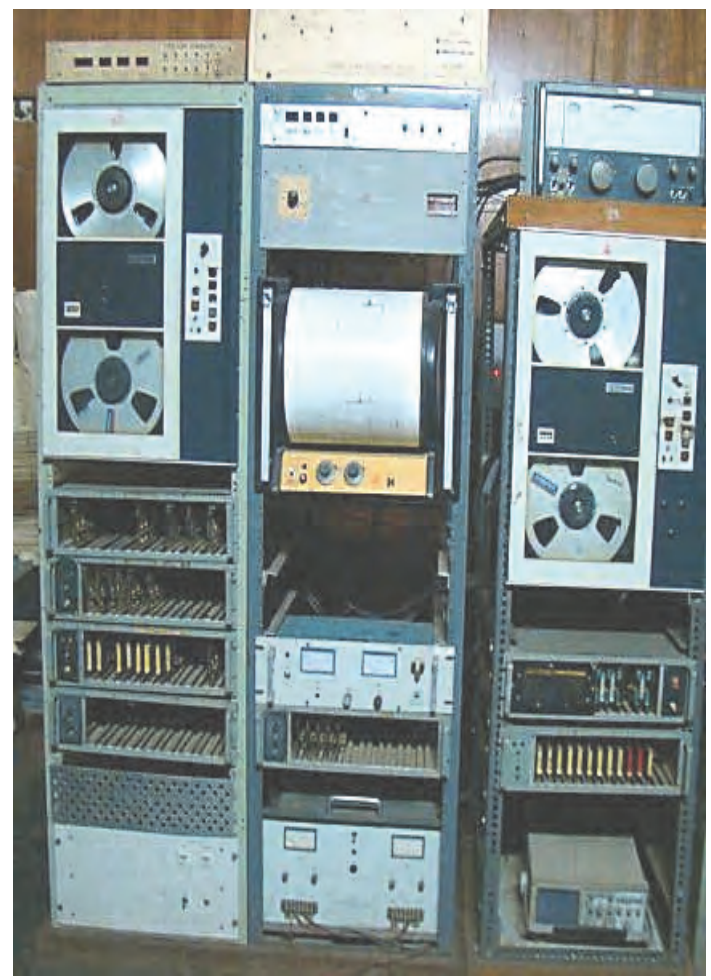

Fig 2.Seismic Recording Unit

This instrument was used in assessing the day-to-day safety of mine workings. The analogue seismic system has been used to continuously monitor and locate seismic events with an accuracy of $+/-30 \mathrm{~m}$ from the mining volume of 8 $\mathrm{km} \times 3 \mathrm{~km} \times 3 \mathrm{~km}$ [6]

The layout of seismic geophone network employed for the monitoring of seismic activities in this period is as shown in Fig.3. It is observed that seismic activity is concentrated in the vicinity of deep-level mine workings of the Champion Reef and Nundydroog mines. The detailed distribution of computed hypocentres of seismic events depth wise along the profile of mine working is shown in the longitudinal section taken along the North-South direction in Fig 4.

More than 10,000 seismic events were recorded with an accuracy of $50 \mathrm{~m}$. The details on the instrumentation and the data generated by this network have been explained by Subbaramu [6]. The seismic data collected was in the analogue form. 


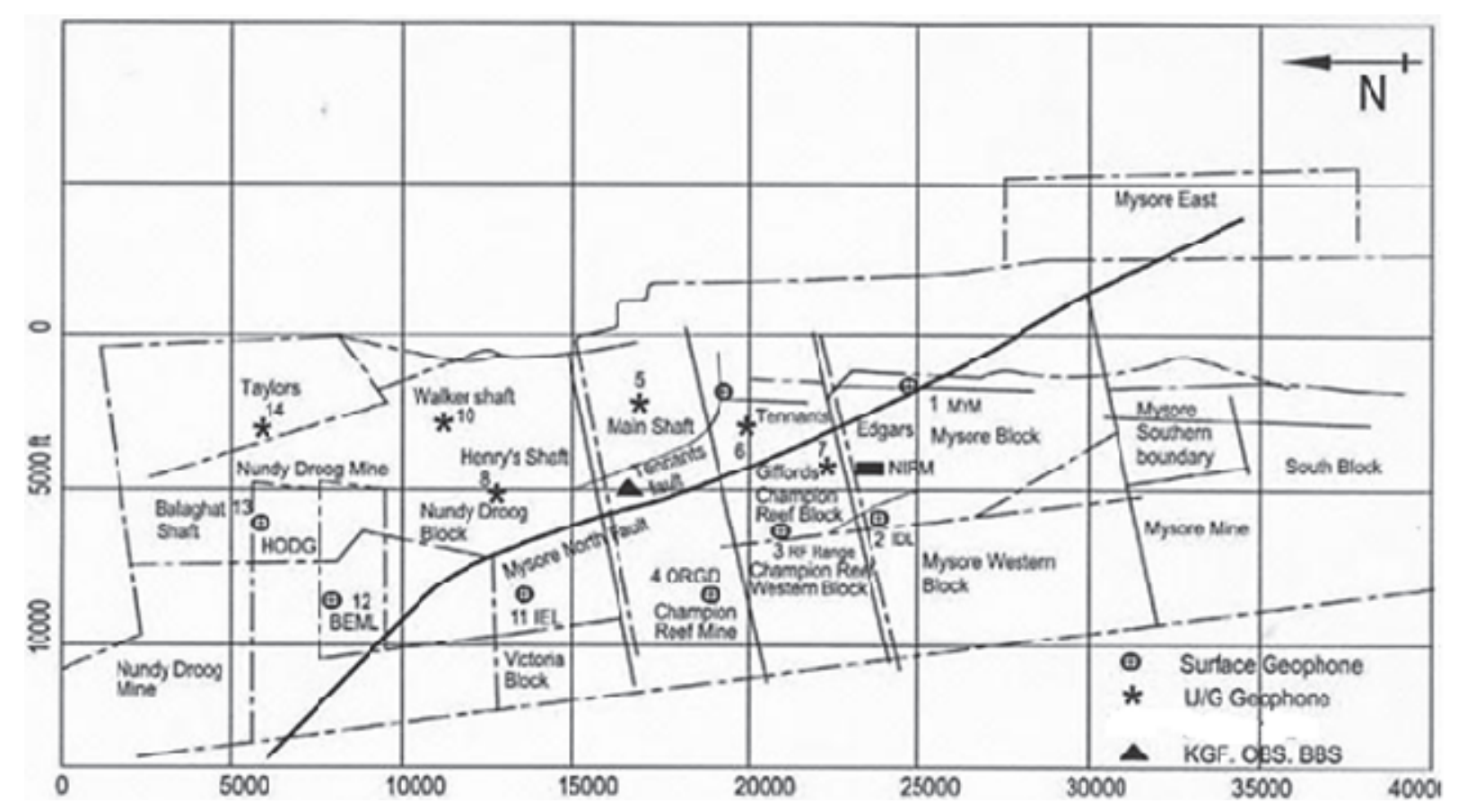

Fig 3 Previously existing seismic network layout [7]

NORTH

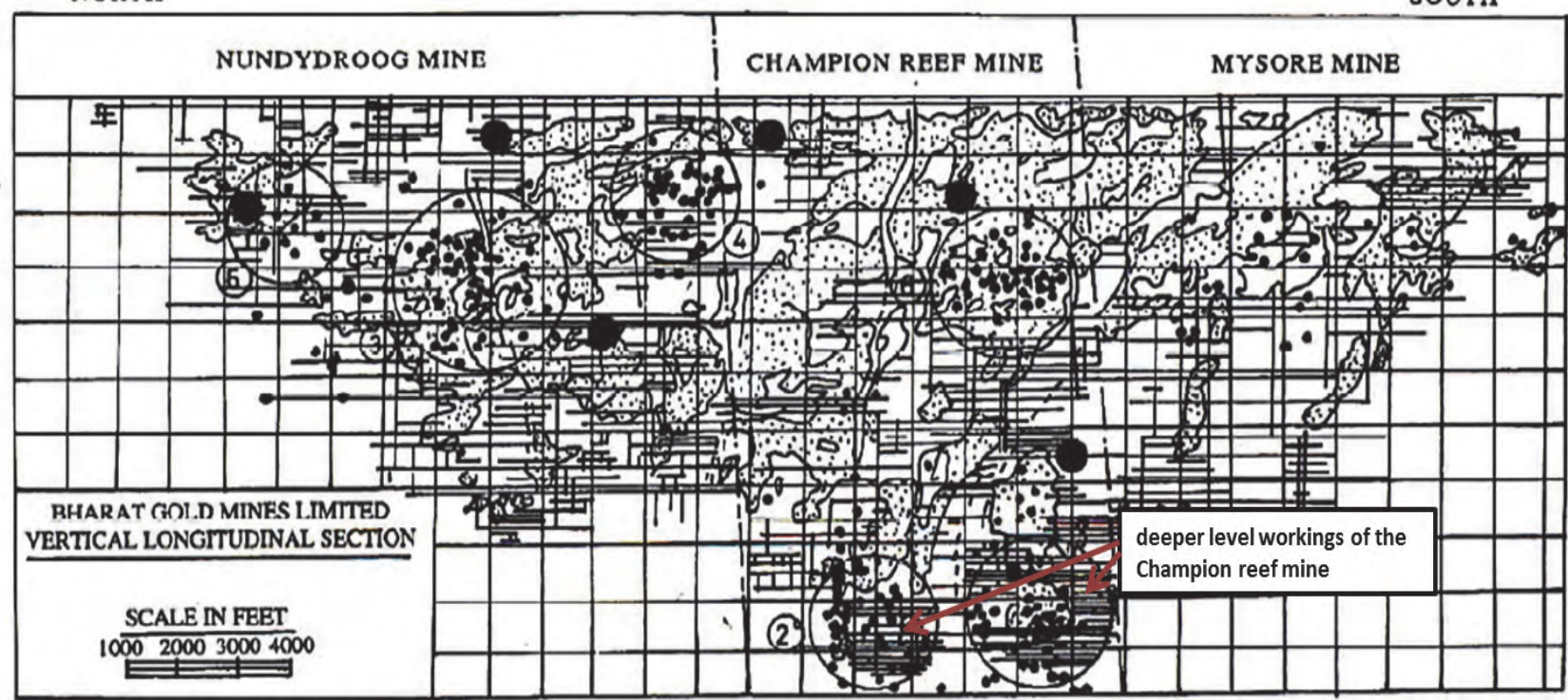

Fig 4.Longitudinal section through Kolar Gold Fields showing typical distribution of seismic events for the year1987 [8]

Seismic Monitoring during 1991 to 1997

The monitoring during this period was continued using the same 14 geophone seismic monitoring system. Microseismic studies were carried out using PDP11/34 and PC-386 computer based online microseismic monitoring systems for investigating the seismicity particularly in Champion Reef deep mine, especially for short range prediction of seismic events and accurate assessment of potential areas of seismicity [9]

Seismic records from 1991 onwards, indicated increase in the level of seismic activity started to increase. The dewatering and pumping out of water regularly from the deeper level mining region was discontinued in 1991, due to the gradual closure of mine working in the deeper level stating economic constraints and reduced deposit availability. The seismic activity could have been triggered by flooding of water within the mines.The regular seepage, collection and gradual spreading of water through critically pre stressed weak zones were identified as reasons for induced seismicity [10]. Detailed investigations identified the event as fluidinduced tectonic seismic event and addressed these events as fluid-induced seismic events in the overburden rock strata. Seismicity induced by effect of water was lubricating the pre-existing geological faults and zones of structural weakness, thereby increasing the pore pressure[10]. 
During this period, it was observed that due to the inundation of water into the deeper level workings, there was an increase in the number of seismic events taking place. The hypocentres of the seismic events were found to be concentrated at two levels: (1) below the water level and (2) close to the water level. With the gradual increase in water level over a period of time, the seismic events were found to concentrate along both sides of champion mine dyke and along the prominent Mysore North fault. There were seismic events also observed in the shallow mine workings during this period. However, the seismicity observed during the period from 1994 to 1997, were found to be very low[10].

Similar case studies were reported by Wetmiller [11] in Falconbridge Mine, Canada, when mining operations were ceased in 1984 mine flooding had started. On closure of the mines, seismic events with magnitude greater than 3 were observed. Board [12], reports a test study in deep level of South African gold mine where small scale seismicity was induced by injecting water along a fault surface.

\section{Seismic Monitoring during 1997 to 2004}

In the year 1997; as an addition to the pre-existing seismic monitoring system, a three component (vertical, north-south and east-west) seismometer - GURLAP broad band system (BBS) was installed specifically to monitor the role of the Mysore North fault in inducing seismicity in the mining area. The broadband system consisted of a sensor CMT 40T and a data acquisition unit $72 \mathrm{~A}-07$ as shown in Fig 5.

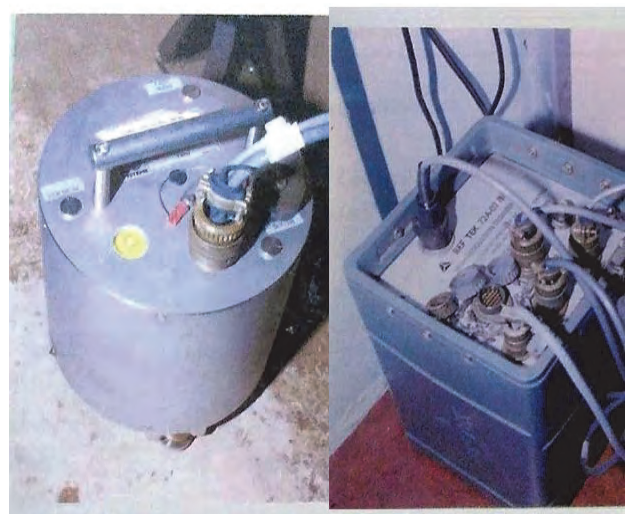

Fig 5.Broadband System - sensor (CMT-40T) and Data Acquisition System (72A-07)

The CMG-40T Triaxial seismometer has low noise and electromagnetic feedback. The system consists of three orthogonal miniature sensors controlled by force feedback to give velocity and mass position electrical outputs. Frequency range used was 0.03 to $30 \mathrm{~Hz}$

A versatile portable 24 bit data digitizer/recorder DAS REFTEK model 72A-07/ND 7821 was connected with the Seismometer. A crystal oscillator in the CPU of DAS provides time to an accuracy of better than 0.5 microsecond/sec. Microseismic studies were carried out by till 1993 using the same PDP11/34 and PC-386 computer based online microseismic monitoring systems. Seismic events have occurred in the presence of water. The cluster of seismic activity on both sides of Mysore North fault is more significant when compared to overall seismic activity in the field.

Even though the mining operation in some of the mines at KGF has been discontinued for quite some time now, the seismic events in the old as well as recent underground workings are frequently occurring at shallow depths upto to a kilometer level where lot of rain water has gradually accumulated over time and spread through excavated area. The present local seismicity in the inundated mining region seems due mainly to strata failure induced by the seepage of water through the weak zones pre stressed to critical limits.

This is consistent with the current picture of mine tectonoseismicity where the seismic sources are found to be clustering in close proximity of NW-SE striking set of geologic faults of which Mysore North fault (MNF) is most prominent as shown in Fig 6.A total of 800 events were recorded using the seismometer. Seismic events recorded are equivalent to micro-earthquakes with maximum local magnitudes range varying from -1.65 to 3.14 .

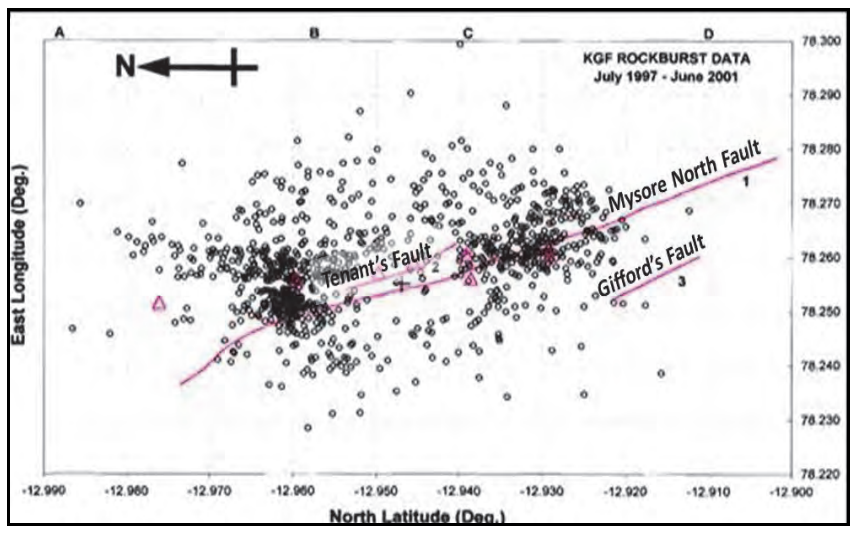

Fig 6.Distribution of computed epicentres of seismic events in the mining region of KGF for period 1997 to 2001[10]

The monitoring of seismic activity was continued keeping in view the slow flooding of the mines as one of the factors affecting the rate of occurrence of the events. The 14 channel seismic geophone network system was in operation till 1998, and then the system was discontinued as it became obsolete.

\section{Seismic Monitoring during 2005 to 2014}

The seismicity of the identified mining region is being monitored using Broadband Seismic system and a Strong Motion Accelerograph (SMA) installed in 2005.Strong Motion Accelerograph was installed [13] in the campus of National Institute of Rock Mechanics. It is a Seismic Data Acquisition system with an internally mounted accelerometer. The strong motion accelerograph - GeoSIG is shown in Fig 7. The SMA is very useful in locating the epicentres of seismic events in and around the abandoned mining region. In the beginning of this period the broadband system was replaced with Trillium compact sensor and Taurus digital seismograph data acquisition unit as shown in Fig 8. 


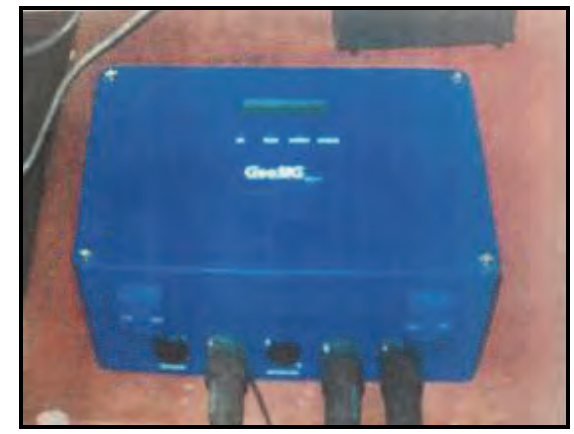

Fig 7.Strong Motion Accelerograph - GeoSIG
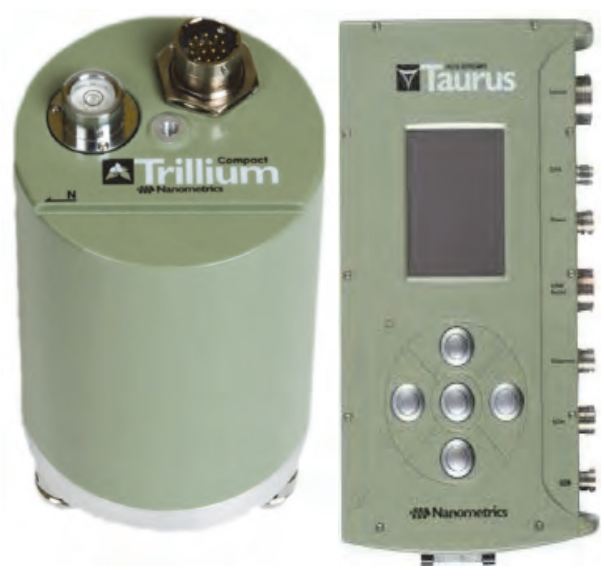

Fig 8.Trillium Compact broadband seismometer and Taurus digital seismograph

The 3 component Trillium 240 sensor having a frequency range of 0.0041 to $35 \mathrm{~Hz}$ with output sensitivity of 1195 $\mathrm{V} / \mathrm{m} / \mathrm{s}$ was installed along with a Taurus 24 bit nanometric data acquisition unit with an internal clock and GPS. Using the Broadband system and the SMA data acquisition and analysis was carried out.

\section{DATA PROCESSING AND ANALYSIS}

In this study, seismic events data for last decade (from the year 2005 to 2014) for the mining region of KGF was analysed. Whenever a seismic event occurs, the strong motion accelerograph records, filters and converts sensor inputs to 18 Bit digital form and saves it in the pre-event memory. The seismic events are being recorded by a single station Strong Motion Accelerograph (SMA), the recorded event is supported by data obtained from the installed broad band system. The recorded event has three components, a vertical component, a North-South component and the EastWest component. All the recorded events were processed for initial zero-line corrections, and the units were scaled. The accelerograms were processed using the seismosignal software for baseline correction to obtain acceleration and displacements. When a seismic event is recorded, depending on the source of the seismic event each component would have recorded the acceleration proportional to the energy from the particular direction. Depending on the phase of Pwave whether it is compressional (upward motion) dilatation (down ward motion) in each component, the quadrant from which the seismic event signal has come was determined.
With the recording of P-wave and the S-wave arrival, the epicentre distance was computed [3]. The magnitude was computed based on the amplitude of P-wave. The seismic events were recorded using this single station for determining the location of the events.

The SMA of the seismic events generated was used to obtain Wood-Anderson synthetic seismograms [2] for accurate and reliable values of local magnitudes. For better analysis of the acquired SMA data, the seismic events occurring at a distance less than $5 \mathrm{~km}$ was considered for analysis.

Based on the period of study taken up for analysis of the seismic events, the total no of recorded seismic events during this period using SMA was 2000 events. The year-wise recorded number of events is given in Table I and presented in Fig 9.

TABLE I: YEAR-WISE NUMBER OF SEIMIC EVENTS RECORDED BY SMA

\begin{tabular}{|l|l|r|}
\hline Sl. No. & Year & No. of events recorded \\
\hline 1 & 2005 & 797 \\
\hline 2 & 2006 & 816 \\
\hline 3 & 2007 & 105 \\
\hline 4 & 2008 & 71 \\
\hline 5 & 2009 & 52 \\
\hline 6 & 2010 & 67 \\
\hline 7 & 2011 & 21 \\
\hline 8 & 2012 & 27 \\
\hline 9 & 2013 & 26 \\
\hline 10 & 2014 & 18 \\
\hline \multicolumn{2}{|l|}{ Total No. of events recorded } & 2000 \\
\hline
\end{tabular}

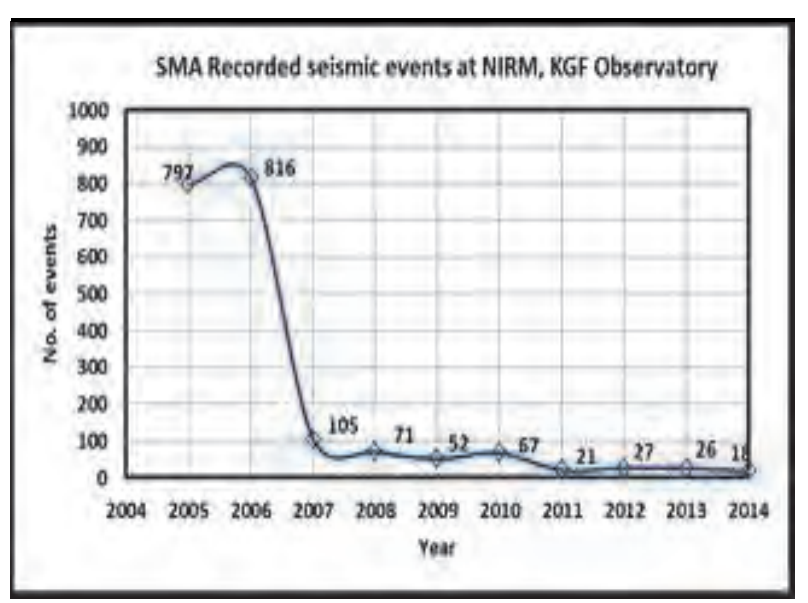

Fig 9. SMA recorded total no. of seismic events for each year

From the Table I, it is very clear that the number. of seimic events recorded during the year 2006 with 816 events is highest and the year 2014 with 18 events shows the lowest number of recorded events. The Fig 9. Shows a gradual decrease in the occurrence of seismic events through the period. This implies that there is a slightly stable condition being met. Year -wise analysis of the seimic events is being 
done in order to study the distribution of events along the radial distance from the site of observation with respect to the seismic magnitude recorded.

Graph plots for visual representation of the distribution of magnitude with respect to the phase and radial distance for the consolidated period of 2007 to 2010 and for the period of 2011 to 2014 is shown in Fig 10 and Fig 11.

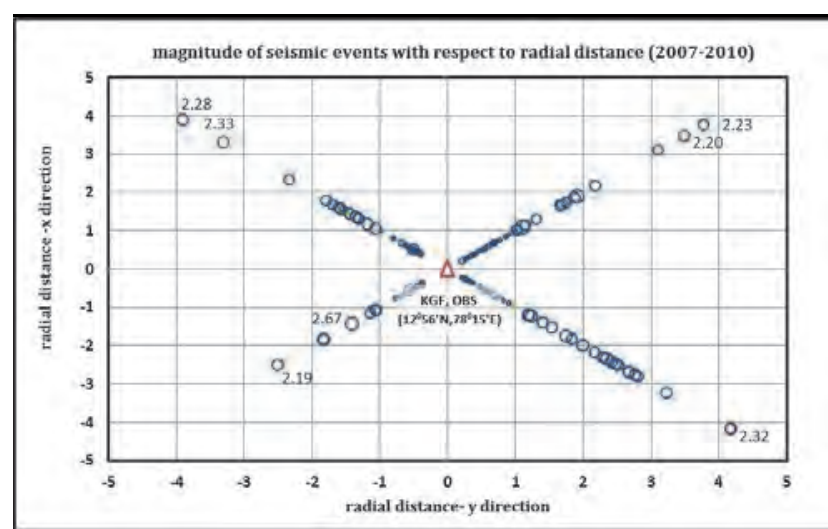

Fig 10. Plot of magnitude with respect to radial distance and phase for the period $2007-2010$

From Fig 10. For the recorded period of 2007 to 2010, the maximum recorded seismic magnitude was 2.32 at distance of $4 \mathrm{~km} \mathrm{SE}$ direction from the recording station. The number of events are more clustered within the radius of 1 $\mathrm{km}$, beyond a radial distance of $3 \mathrm{~km}$ the events are few and scattered pattern is observed

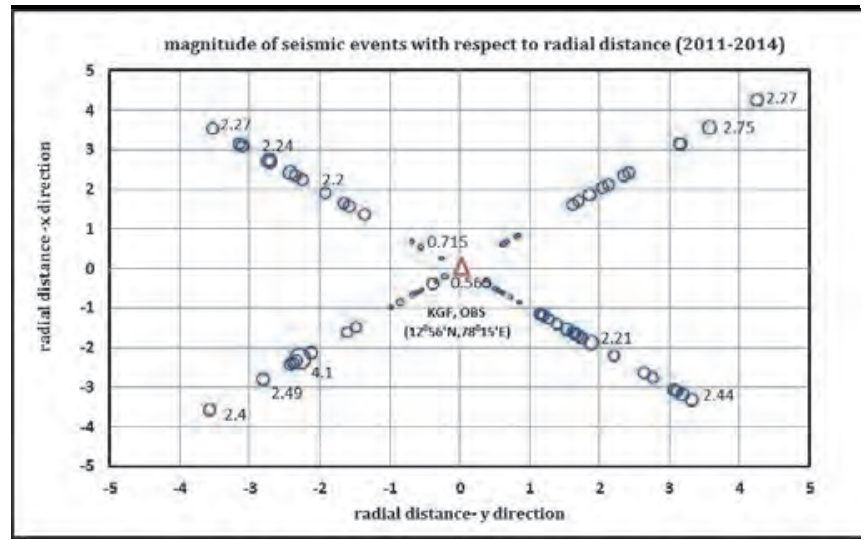

Fig 11. Plot of magnitude with respect to radial distance and phase for the period 2007-2010

From Fig 11. For the recorded period of 2011 to 2014, the maximum recorded seismic magnitude was 2.27 at distance beyond $4 \mathrm{~km}$ NE direction from the recording station. The number of events are evenly distributed upto radius of $2 \mathrm{~km}$, beyond a radial distance of $3 \mathrm{~km}$ the events few and scattered pattern is observed

The above observations were for consolidated periods of four years each. The patterns observed indicates seimic events that have occurred during the period are in close proximity to the MNF which lies about $3 \mathrm{~km}$ from the site of observation. For even better understanding of the distribution of the seimic events radially with respect to the seismic magnitude obtained, graphs were plotted to show the clustering of events at various locations. Magnitude with respect to radial distance from site of observation for two to three consecutive years are shown in Fig 12, Fig 13, Fig 14 and Fig 15

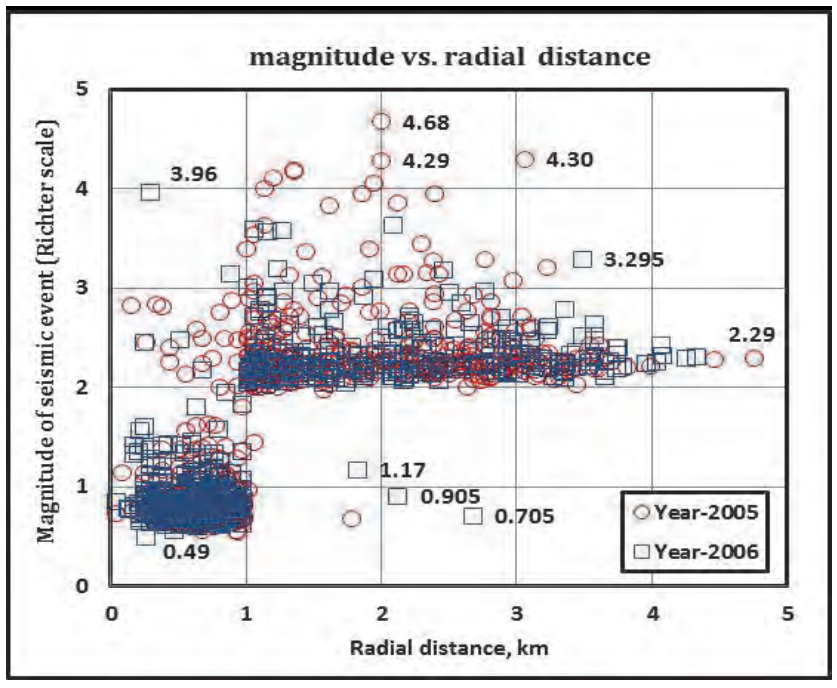

Fig 12.Plot of magnitude vs. radial distance for the year 2005 and 2006

From Fig 12, the maximum magnitude recorded is 4.68 at a radial distance of $2 \mathrm{~km}$. seismic event clusters are observed within a radial distance of $1 \mathrm{~km}$ with magnitude varying between 0.5 to 1.5.There is a second cluster of events covering a radial distance of $1 \mathrm{~km}$ to $4 \mathrm{~km}$ of magnitude ranging between 2 to 3 . All the other events are evenly distributed upto a distance of $5 \mathrm{~km}$.

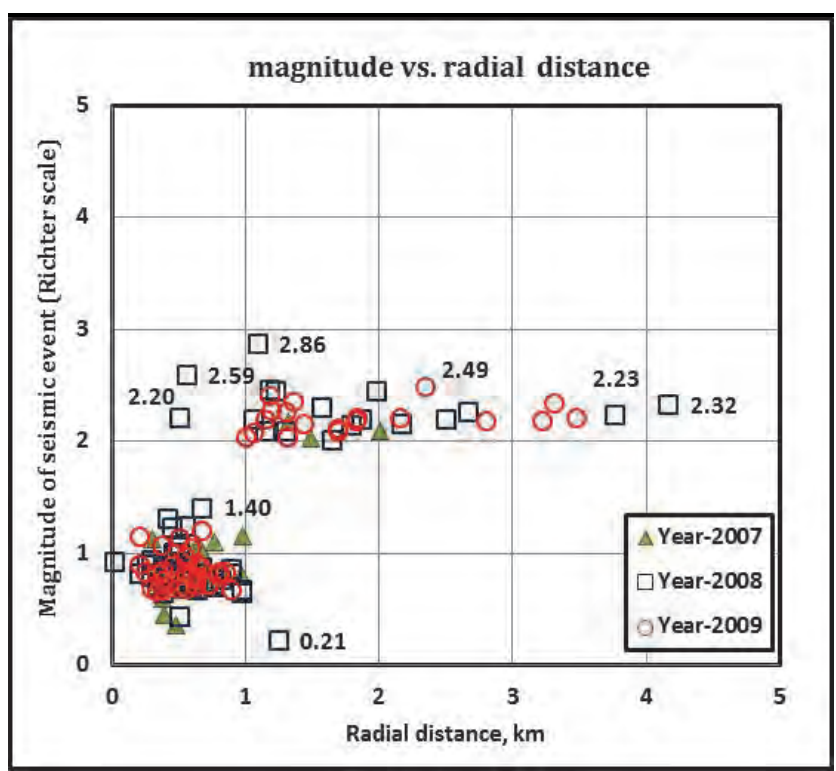

Fig 13.Plot of magnitude vs. radial distance for the year 2007, 2008 and 2009

From Fig 13, the maximum magnitude recorded is 2.86 at a radial distance of $1 \mathrm{~km}$. seismic event clusters are observed within a radial distance of $1 \mathrm{~km}$ with magnitude varying 
between 0.6 to 1.2.There is a second evenly distributed cluster of events covering a radial distance of $1 \mathrm{~km}$ to $2 \mathrm{~km}$ of magnitude ranging between 2 to 2.5 . All the other events are found scattered.

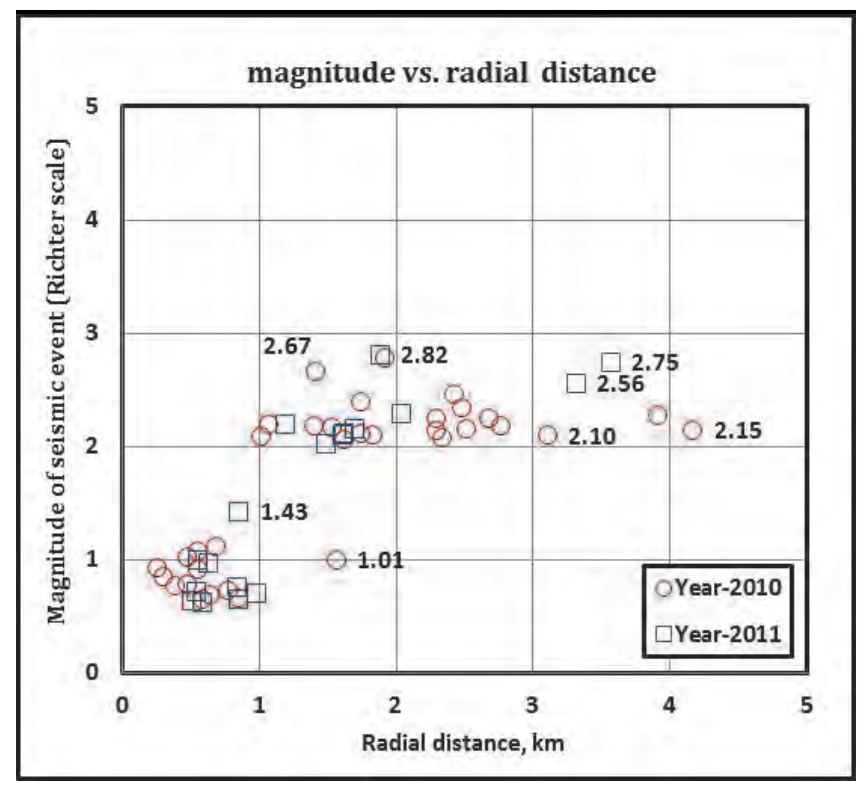

Fig 14.Plot of magnitude vs. radial distance for the year 2010 and 2011

From Fig 14, the maximum magnitude recorded is 2.82 at a radial distance of $1.9 \mathrm{~km}$. slight seismic event clustering is observed within a radial distance of $1 \mathrm{~km}$ with magnitude varying between 0.8 to 1.0 .It is to be noted that the number of seismic events have reduced drastically when compared to events recorded for the year 2005 and 2006 seen previously, the other remaining events are found scattered.

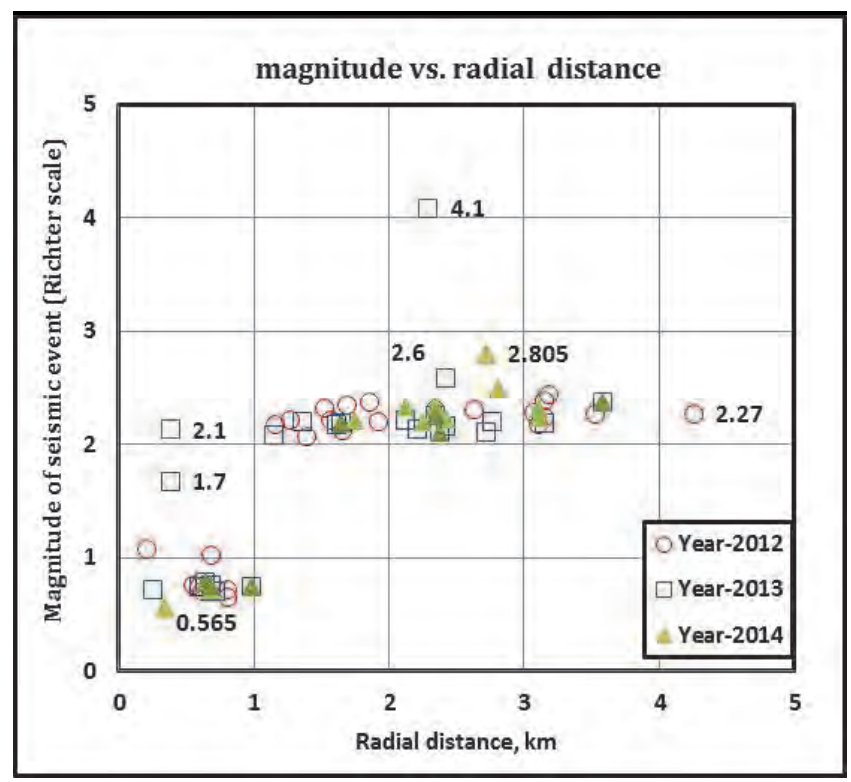

Fig 15.Plot of magnitude vs. radial distance for the year 2012, 2013 and 2014

From Fig 15, the maximum magnitude recorded is 4.1 at a radial distance of $2.3 \mathrm{~km}$. slight seismic event clustering is observed within a radial distance of $1 \mathrm{~km}$ with magnitude varying between 0.7 to 0.9 .It is noted that in this period of monitoring also the number of seismic events recorded have reduced, the other remaining events are found scattered.

From the analysis of data with respect to the period of analysis from 2005 to 2014 , it is found that the maximum numbers of seismic events have occurred in close proximity to the major prominent Mysore North Fault lying approximately at a distance of $0.5 \mathrm{~km}$ to $1 \mathrm{~km}$ and some found close to shallow level of workings. Since the observed seismic events were found to occur at shallow depths

\section{DISCUSSION}

This single station strong motion accelerograph was used in monitoring the seismic events after the closure, the events were continuously recorded. The recorded event is supported by data obtained from the installed broad band system. From this study it can be deduced that:

1. For the SMA recorded period of 2005 to 2014, the maximum magnitude recorded is 4.68 at a radial distance of $2 \mathrm{~km}$. seismic event clusters are observed within a radial distance of 1 to $2 \mathrm{~km}$ with magnitude varying between 0.5 to 1.5

2. It is observed that the year 2006 has the highest recorded number of events with 816 events and the least number of events were recorded in the year 2014 with 18 events. Though, there has been an overall reduction in the number of events recorded, there certainly has been growing concern as the tremors are felt at irregular intervals leading to apprehension among civil community. The intensity of tremors felt are likely more when the source location of the seismic events become shallower.

3. The intensity of seismic events and their rate of occurrence may be directly related to the old mining workings and the geological fault present in the mining region.

4. Seismic events having magnitude less than 3 can be referred to as micro-earthquakes, since the ground vibrations produced by micro-earthquakes are of low levels, not felt by human beings nor is their intensity large enough to cause any visible damage to the surface structures

Based on the above results, the magnitude with respect to the radial distance and the number of seismic events or the rate of seismic events serve as an indicator for possibility of hazard to the structures closer to the high event locations. However, the number and the magnitude alone does not contribute to evaluating the potential hazard, as it is required to understand the actual intensity of the vibration or the shake imparted by the sudden release of energy and its depth[14]. In the present case, since only one station has been available to provide data and this is incomplete for arriving at quantification of any parameter to evaluating hazard. In case of limited data, without involving deeper analysis, calculation of magnitude based on maximum magnitude and the nearest second largest magnitude values in a time window can be done. Thus, qualitative analysis based on number of events $\left(S_{n}\right)$ over a time window i.e frequency of events and their magnitude $\left(\mathrm{M}_{\mathrm{t}}\right)$ above certain 
threshold value is an option to understand possible potential hazard due to the seismic events. The simplest formula for the assessment of the seismic activity rate $=n / T$ [14]. Magnitude can be estimated based on empirical relationships between the magnitude, observed tectonic features, or using frequency of events and magnitude curves and the use of strain rate or rate of seismic moment release. The values of magnitude arrived based on any one these techniques can have impact on the quality on the assessment of hazard.

Statistical techniques can be used with the historical data to assess the possible hazard due to the seismic events and can be useful to evaluate change in the level of seismicity in the mining area. These techniques consider probability of occurrence of seismic event, recurrence of a possible event and maximum expected magnitude. There are also nonstatistical approaches based on seismic energy released and the rate of seismic activity. While the statistical technique generally be reliable based on activity inclusion from the whole mining area, the non-statistical one is applicable for part of the mine using changes in the seismic source parameters and finding out dangerous seismic event threshold level. While in the efforts to assess the hazard due to the events, it has been found that $[15,16]$ magnitude alone do not play role, but there needs to be inclusion of geological, geotechnical and the changes in the stress regime in the mines.

\section{CONCLUSION}

Since the beginning of mining activities, the monitoring of the seismic events has been done through employment of seismic or microseismic systems. Micro-earthquake monitoring networks are well suited for studying seismically active areas including study of rockbursts. With the limitations of having a single station only the epicentres of the seismic events can be computed and the depth at which the seismic event takes place cannot be arrived at accurately. Therefore, the results discussed are an estimate based on the trend observed and can be verified only when the seismic event is large enough to cause a visible surface damage.

In order to locate the actual source of individual seismic event along with its corresponding depth and to assess the hazard due to abandoned mine, a network of minimum 5 to 6 geophones should be deployed and monitored.

\section{ACKNOWLEDGEMENT}

The authors are thankful to the Director, NIRM for permitting to publish the paper in the conference. The authors are also thankful to the Department of Science and Technology, New Delhi for installation of strong motion accelerograph along with a Broad Band Seismic Monitoring station.

\section{REFERENCES}

[1] R Krishnamurthy, Rockburst research in the Kolar Gold Fields. Proc. Symposium on use of Gauribidanur data for seismological research, Bhabha Atomic Research Centre, Seismic Arrary Station, Gauribidanur, pp.79-88, 1969

[2] C Srinivasan, Y A Willy,A Harbindu and M L Sharma, Strong Ground Motion Prediction Equation for low Magnitude and Nearfield Earthquake data for Shield region in India, Proceedings of the 15th World Conference on Earthquake Engineering, Lisbon (PT), 2012

[3] S Malliga, Source Location of Rock Burst in the Mines of Kolar Gold Fields, International Journal of Science and Research (IJSR) ISSN (Online): 2319-7064, 2013

[4] R.J. Durrheim, R.L. Anderson, A. Cichowicz, R. Ebrahim-Trollope, G. Hubert, A. Kijko, A. McGarr, W.D. Ortlepp and N. van der Merwe, The Risks to Miners, Mines and the Public posed by Large SeismicEvents in the Gold Mining Districts of South Africa, Proceedings of the Third International Seminar on Deep and High Stress Mining, 2-4 October 2006, Quebec City, CANADA.

[5] R Krishnamurthy, and C. Srinivasan, Current seismic studies for the detection of rockbursts in Kolar Gold Fields, Indo-German Workshop on Rock Mechanics, NGRI, Hyderabad, 1980

[6] K R Subbaramu et al, Seismic investigation of rockburst in the Kolar Gold Fields, Proc. 4th Conf. on AE/MS Activity in Geological structures and materials, Pennsylvania, 1985

[7] Chinnappa Srinivasan, Yesurathenam Willy, Iswar Gupta, Estimation of local magnitude of rockbursts using strong motion accelerograms in the mines of Kolar Gold Fields, Acta Geophysica. Volume 58, Issue 2, Pages 300-316, ISSN (Online) 1895-7455, ISSN (Print) $1895-6572,2010$

[8] C Srinivasan, S K Arora and R K Yaji, Use of Mining and Seismological parameters as premonitors of rockburst, Int. J. Rock Mech. Min. Sci. Vol.34, No. 6, 1997

[9] N M Raju, P C Jha, C Srinivasan et.al, Combating the problems of rockburst at kolar gold fields,Journal of mines, metals and fuels, vol XXX, No.11-12, pp. 370-376, 1991

[10] C Srinivasan, S Benady, and C Sivakumar, Fluid induced seismicity in Kolar Mining Region. In: Proc. Workshop on Dam Safety Including Instrumentation of Dams, 15-17 November, 2000, Trivandrum.

[11] Wetmiller, R.J., C.A. Galley, and M. Plouffe, Post-closure seismicity at a hard-rock mine, Rockbursts and Seismicity in Mines (R.P. Young, Ed.), Balkema, Rotterdam, pp. 445-448, 1993.

[12] Board, MT Rorke, G Williams and N Gay, Fluid injection for rockburst control in deep mining in Proceedings of the US Symposium on rock mechanics, J R and Wawersik, W R , 111-121, Balkema, Rotterdam, 1992

[13] C Srinivasan, Yesurathenam A. Willy, and C. Sivakumar, Strong motion studies in the mines of kolar gold fields, Monitoring Research Review: Ground-Based Nuclear Explosion Monitoring Technologies, 2008

[14] A Kijko and CW Funk, The assessment of seismic hazards in mines, The Journal of the South African Institute of Mining and Metallurgy, July 1994.

[15] PS Piper, An assessment of backfill as a means of alleviating the rockburst hazard in deep mines. M.Sc. Thesis, University of the Witwatersrand, Johannesburg, South Africa, 1991.

[16] McGarr, A., Green, R.W.E. and Spottiswoode, S.M. 1981. Strong ground motion of mine tremors: some implications for near-source ground motion parameters. Bull. Seism. Soc. Am. 71:295-319. McGarr, A., Spottiswoode, S.M. and Gay, 1975. Relationship of mine tremors to induced stresses and to rock properties in the focal region. Bull. Seism. Soc. Am. 65:981-993. 